\title{
The Planners' Perspective on Train Timetable Errors in Sweden
}

\author{
Carl-William Palmqvist $\mathbb{D}^{1},{ }^{1}$ Nils O. E. Olsson, ${ }^{1,2}$ and Lena Winslott Hiselius ${ }^{1}$ \\ ${ }^{1}$ Faculty of Engineering, Lund University, P.O. Box 118, 22100 Lund, Sweden \\ ${ }^{2}$ Norwegian University of Science and Technology, Høgskoleringen 1, 7491 Trondheim, Norway \\ Correspondence should be addressed to Carl-William Palmqvist; carl-william.palmqvist@tft.lth.se
}

Received 20 November 2017; Revised 5 February 2018; Accepted 8 March 2018; Published 12 April 2018

Academic Editor: Lingyun Meng

Copyright ( 2018 Carl-William Palmqvist et al. This is an open access article distributed under the Creative Commons Attribution License, which permits unrestricted use, distribution, and reproduction in any medium, provided the original work is properly cited.

\begin{abstract}
Timetables are important for train punctuality. However, relatively little attention has been paid to the people who plan the timetables: the research has instead been more centred on how to improve timetables through simulation, optimisation, and data analysis techniques. In this study, we present an overview of the state of practice and the state of the art in timetable planning by studying the research literature and railway management documents from several European countries. We have also conducted interviews with timetable planners in Southern Sweden, focusing on how timetable planning relates to punctuality problems. An important backdrop for this is a large project currently underway at the Swedish Transport Administration, modernizing the timetable planning tools and processes. This study is intended to help establish a baseline for the future evaluation of this modernization by documenting the current process and issues, as well as some of the research that has influenced the development and specifications of the new tools and processes. Based on the interviews, we found that errors in timetables commonly lead to infeasible timetables, which necessitate intervention by traffic control, and to delays occurring, increasing, and spreading. We found that the timetable planners struggle to create a timetable and that they have neither the time nor the tools required to ensure that the timetable maintains a high quality and level of robustness. The errors we identified are (a) crossing train paths at stations, (b) wrong track allocation of trains at stations, especially for long trains, (c) insufficient dwell and meet times at stations, and (d) insufficient headways leading to delays spreading. We have identified eleven reasons for these errors and found three themes among these reasons: (1) "missing tools and support," (2) "role conflict," and (3) "single-loop learning." As the new tools and processes are rolled out, the situation is expected to improve with regard to the first of these themes. The second theme of role conflict occurs when planners must strive to meet the demands of the train operating companies, while they must also be unbiased and create a timetable that has a high overall quality. While this role conflict will remain in the future, the new tools can perhaps help address the third theme by elevating the planners from first- to double-loop learning and thereby allowing them to focus on quality control and on finding better rules and heuristics. Over time, this will lead to improved timetable robustness and train punctuality.
\end{abstract}

\section{Introduction}

Railways are an important part of the transport system. In Sweden, trains traveled 153 million km during 2015, which is an increase of $9 \%$ over five years [1]. Passenger traffic has increased by $16 \%$ over the same period, and in 2015 passenger trains made up $83 \%$ of all trains. While freight traffic in 2015 was at the lowest level since 1990, the freight tonnage transported by rail has risen slightly as the loads have increased. The capacity is most heavily utilised around the three major metropolitan areas of Stockholm, Gothenburg, and Malmö-Lund. A quarter of the metropolitan lines is utilised at levels associated with high sensitivity to delays, low average speeds, and little time for infrastructure maintenance [2]. On the rest of the network, only about five percent of the segments are utilised to the same extent. When measured during peak loads, these figures are higher across the board.

The punctuality of trains in Sweden has been close to $90 \%$ for the last several years [1], with punctuality measured as a maximum delay of five minutes at the final stop. This is considered too low by the industry, which has set a goal that it should be $95 \%$ by 2020 . This ambition, to increase punctuality, is the background for our research and for this paper. Many factors influence punctuality, such as 
weather [3-5], congestion [6], other operational factors [7, 8], and infrastructure [9]. Previous studies also indicate that properties of the timetable can have a large impact on delays and punctuality, that delays often occur at station stops, and that dwell times are systematically underestimated [10-13]. Thus, there is reason to believe that errors in the timetable may affect punctuality.

The interaction between infrastructure, capacity, and timetable planning is found on a strategic, tactical, and operational level. The strategic level is typically long term, over several years, and can be related to new infrastructure or new timetable structures, while the tactical level is related to producing a timetable implemented in a shorter perspective, typically one year. This paper mainly studies tactical timetable planning. Operational timetabling is related to making shortterm changes to a timetable, often a few weeks or days in advance.

Timetable planners prepare timetables and other documentations related to planned changes for passenger and freight trains. Planners are often faced with the challenges of working with complex timetabling [14]. In addition to the complexity of the planning itself, they must be able to deal with different stakeholders in the railway sector and have conflict resolution skills. A final timetable must satisfy the needs of travelers and public and private parties, while maintaining the fairness, transparency, reliability, and safety of the railway system. The train service specifications are passed to the timetable planners, who produce the timetables. However, these specifications can be in violation of guidelines, or there can be conflicting needs of different train operators. Watson [14] found that the complexity of the timetabling and capacity allocation processes can hinder effectiveness, highlighting the conflicting nature of objectives for timetable planning, especially in the privatized railway.

While extensive research has been carried out on the human-machine interface in train traffic control in Sweden ([15-17]; see also [18] for dispatchers in the US) and some work has been done on the integration of timetable planning and traffic control [19], relatively little research has been done focusing on timetable planners and their tools. Watson $[14,20]$ covered timetable planning in the UK, which has many similarities to the Swedish context, and ONTIME [21] contains some expert judgment on the state of practice in Sweden. National interest in this topic has increased, as a large project is currently in progress at the Swedish Transport Administration, seeking to modernize the interface between train operating companies and the Transport Administration by developing new tools and routines for timetable planning. These tools will, among other things, support more flexible and optimal planning, improve capacity and punctuality, shorten planning lead times, and improve transparency and the handling of engineering works [22]. Since 2011, the situation with the deregulated passenger train market in Sweden is also new and rare in an international context, with the new divisions of responsibility resulting both in new role conflicts and in more collaborative decision-making between stakeholders. To learn more about this, it is useful to talk to the timetable planners.
As the timetable planning process and methods in Sweden are about to undergo significant change over the next few years, this paper (1) presents the state of practice in order to establish a baseline and (2) outlines the state of the art in research, which has inspired and influenced the development of the new tools and methods. It also (3) gives a description of the timetable planners current situation in Sweden and (4) identifies common errors in Swedish train timetables, which influence the punctuality, as well as the reasons behind them. Thereby, the paper helps to enable future studies looking to evaluate the effects and effectiveness of the new tools being developed and implemented for train timetable planning in Sweden and elsewhere.

\section{Background}

Timetabling has largely been studied from a technical and optimisation perspective (see, e.g., [24]). However, timetabling can also be studied from an organizational perspective, using other methods. For instance, Avelino et al. [25] study the politics of timetabling, comparing the Dutch and Swiss experiences and illustrating that "timetable planning is not merely an operational process to be left to engineers or economists" (pp. 20). Even though the Swiss have many more train operating companies than the Dutch, their federal government still takes a much more active and strategic role in ensuring an optimised travel time over the whole network. Watson [14] found that the privatization of British Rail had a negative effect on the timetabling processes. The problems were a result of poor planning and rushed implementation of new organization of the British railway sector. Since then, both the British and Swedish railways have gained experiences from the new structures with a division between infrastructure and train operation. However, the inherent characteristics of the divided structure remain.

The infrastructure manager supplies capacity on the railway, while train operating companies represent the demand for transport. Timetable planners are squeezed in between these needs, which sometimes conflict [26]. Watson [14] discusses timetable planning as a process by which a "demand" for rail transport (passenger and freight) is connected to the "supply side" constraints (especially available infrastructure capacity) in order to produce timetables that meet the demand. Through train planning, railway administrators seek to meet the needs of customers while utilising available resources as well as possible. Efficient and effective train planning is the key to getting the best possible performance on a railway network.

Timetabling is governed by several restrictions, such as safety requirements and organizational policies. A routine or heuristic approach can be applied to timetabling. Routines can be defined as "a repetitive, recognizable pattern of interdependent actions, involving multiple actors" [27, pp. 96]. Heuristics [28] are cognitive rules of thumb, or shortcuts, that people apply, consciously or unconsciously [29]. Argyris and Schön [30] present learning as understanding and eliminating the gap between the expected result and the actual result of an action. This gap can be eliminated either by making changes (taking corrective measures) within the 


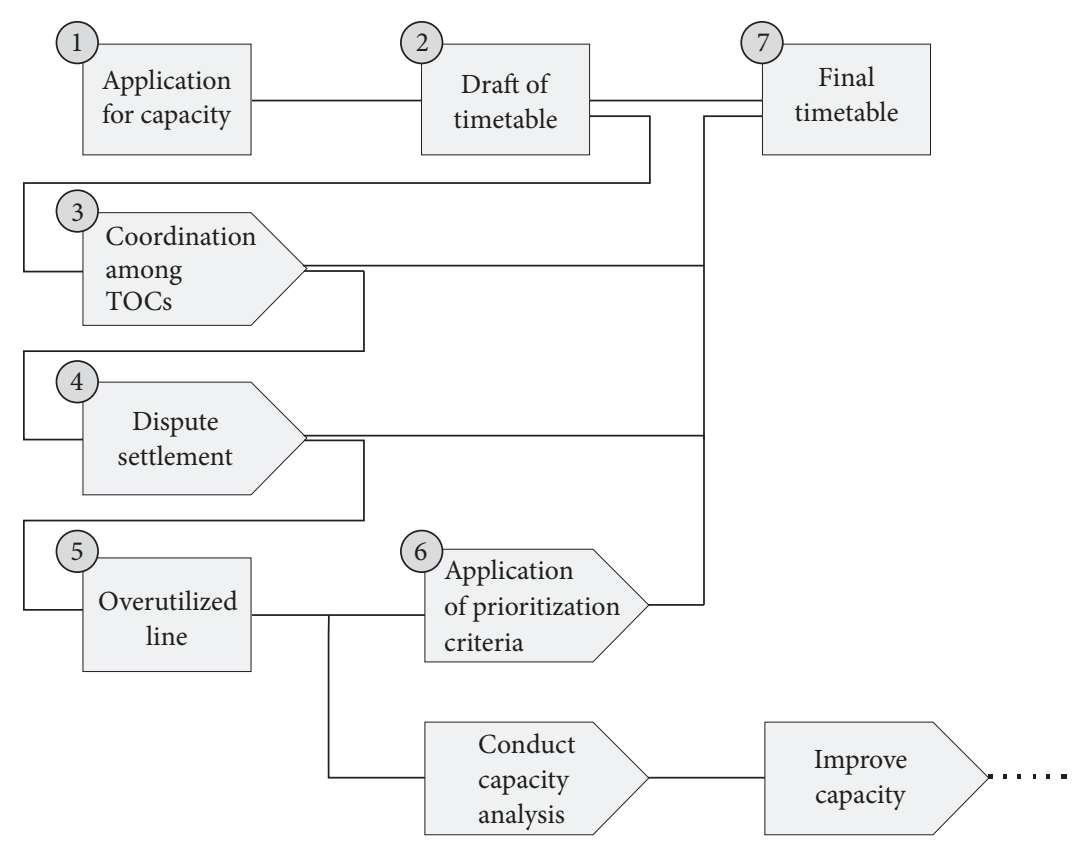

FIgURE 1: Capacity allocation process in Sweden. Adapted from the Swedish Transport Administration [23].

existing values and norms, or by changing the existing values and norms. The former is called single-loop learning and the latter is called double-loop learning. Single-loop learning is connected to doing things right, in accordance with the existing values and norms. Double-loop learning is about doing the right things, by questioning the existing values and norms. This is a concept we will return to throughout the paper.

According to Loock and Hinnen [31], organizational heuristics are the result of collective learning processes. They found that successful organizations refine their heuristics over time, as a result of feedback loops. Organizational heuristics can also interact with individual heuristics and with improvisation in the decision-making process [32]. Kirkebøen [33] shows that heuristics can be biased, such as a bias to rely on the information that is most available or a bias to search for information that confirms rather than contradicts a decision.

Managerial issues in railway planning have been the topic of a range of publications, notably Vuchic [34] and Profillidis [35]. Managerial aspects of railway planning include strategic, tactical, and operational issues, and timetabling is an important factor in all these perspectives. A strategic perspective on railway planning includes selecting major investments and positioning the railway within the overall transport system, as described by Harris et al. [36]. In a tactical perspective, timetabling is one step in the planning process. Ceder [37] describes the train scheduling process in four steps: network route design, setting timetables, scheduling vehicles, and assignment of crew. All of these planning steps have been of interest to researchers, especially from an optimisation perspective [38]. Operational management issues in railway planning have also been studied: Veiseth et al. [39] study how timetable improvements in a Total Quality Management perspective for operational improvements, and Samà et al. [40] provide an example of applying optimisation to support operational management. Roth et al. [18] and Tschirner [41] also studied aspects of operational management for train dispatching in traffic control centres, while Watson $[14,20]$ considered the contrasting needs and preferences of timetable planners and their managers.

2.1. State of Practice in Sweden. The following is an outline of the current state of practice in Swedish train timetabling, to give the reader a better understanding of the processes and tools involved. Rail traffic in Sweden has been gradually deregulated since competition for some tracks for passenger trains was allowed 1990, with open access with competition on all tracks since 2011, while freight services have been competing on the tracks since 1996 [42].

2.1.1. The Capacity Allocation Process. The annual capacity allocation process in Sweden is illustrated briefly in Figure 1, which is reconstructed from the Network Statement published by the Swedish Transport Administration. This corresponds to the tactical level of planning described above. The process as described here is based on the Network Statement published by the Swedish Transport Administration [23] and an excellent account in Hellström [19]. First the train operating companies send in requests for the capacity they want during the next year. The timetable planners at the Transport Administration combine these requests and, by following their rules and guidelines for how to plan timetables, come up with a draft that contains all the train timetables for one year. In case there are conflicting requests, such that not all trains can be run when and where the train operating companies desire, there is first a step where the parties are encouraged to coordinate among themselves. If 
this coordination is unsuccessful, there is a process where the Transport Administration, together with the parties, tries to settle the dispute. If these attempts are also unsuccessful, parts of the infrastructure can be declared to be saturated, and the planners at the Transport Administration use prioritization criteria to determine which trains have priority, sometimes entirely rejecting the other requests. In yet another step, the train operating companies can appeal the decision of the planners to an administrative court, if they are unsatisfied with the planners' decisions.

The point of departure compared to other European countries is when the coordination process breaks down. The United Kingdom [43] has a more qualitative process with an overarching objective "to share capacity on the Network for the safe carriage of passengers and goods in the most efficient and economical manner in the overall interest of current and prospective users and providers of railway services." Along with this objective it has a list of twelve criteria, on which to assess the fulfilment of the objective. In Germany [44], priority is given to regular-interval or integrated network services, cross-border trains, and train paths for freight trains. If none of these criteria are sufficient, priority is given to the train paying the higher track charge. In the Netherlands [45], the track charges for the conflicted train path are raised if an agreement cannot be found by the parties, to the point that only one of the actors remains. The Dutch also emphasize the basic hourly patterns in their capacity allocation process, striving for a cyclic timetable, something that is not found in the other countries' process descriptions.

How trains are prioritized in the timetabling is regulated in the Network Statement [23]. In the request for capacity, the train operating companies must classify their trains according to previously set criteria. For passenger trains, the expected number of passengers, the share of passengers who are time-sensitive, the share of regional travelers, and demands for high speeds are the basis for this categorisation. Similar criteria are used for freight trains. There are 18 categories for passenger trains, shown in Table 1, and 15 for freight, which are not shown here. Trains can also have associations with other trains: these are categorised into five categories each for passenger and freight, based on the number of passengers or tonnage of freight, and three categories for the turnaround of vehicles. Each prioritization category is linked to a series of social cost estimates, which are based on the methodology in ASEK [46] and are used to find a total solution, which minimises the social welfare costs. Track charges to be paid by the train operating companies to the Swedish Transport Administration are determined using other methods and are not in any way involved in the prioritization of trains.

Sometimes train path requests, or associations, are not possible to fulfil, and they are instead excluded from the timetable. While there is no clear guidance from welfare economic theory on how to evaluate these exclusions [47], a cost is still assigned so that large numbers of trains are not simply excluded. The cost estimate has instead been calculated roughly in the following way: for each type of train (each prioritization criteria) an estimate has been made based on how much the travel time can be extended before it is no longer considered viable to operate the train at all. For commuter and regional trains, this has been set to $15 \%$, so that if the travel time of a train had to be extended by more than $15 \%$, it is assumed that no one would like to use that train (there is no documentation or discussion on how these limits have been determined). The cost of excluding a train is then set to be equal to the cost of such a train being run to that maximum limit, which results in a very high cost of excluded train paths, severely punishing solutions that deny requests for capacity. A minor detail in the calculation of exclusion costs is that a template is applied to estimate a reasonable level of margins for the trains, instead of using the actual size of margins in the train path. This is done so that companies do not act strategically in reducing margins in order to have their competitors' trains be excluded instead of their own.

2.1.2. Robust Timetables. Robustness in timetables is primarily achieved by modifying time supplements, headways, and dwell times (see, i.e., [48]). In Sweden, time supplements are added in several ways. The first way is included in the runtime calculation, which is calculated as if the train had a technical top speed 3\% lower than it does. Practically speaking, this adds a uniformly distributed margin of 3\%. This is often motivated by differences in train driver behaviour and is described as the primary source of margins in timetables but in fact only makes up a small fraction of the total margins [49].

The other explicit way to add time supplements is by assigning node supplements [50]. On each major railway line, between two and four stations have been designated as nodes, while minor lines instead use the first and last stations. The idea is then to add a number of minutes as time supplements for trains traveling between two nodes. For passenger trains, those that have maximum speeds above $180 \mathrm{~km} / \mathrm{h}$ need four additional minutes between each pair of nodes, and those that have lower maximum speeds instead need three minutes for each pair of nodes. Trains that travel shorter distances on the major lines, not reaching a node, require two minutes. The airport express trains are given an exception, only needing node supplements of one minute. Freight trains require two minutes for each set of nodes, or one minute for shorter distances.

In addition to these two methods, timetable planners use their discretion in assigning time supplements. One common practice is to add seconds, so that arrival times occur at whole minutes. For instance, if a train would arrive at 12:44:27, the planner might add 33 seconds, so that the arrival instead occurs at 12:45:00. Over long journeys, this often adds up to considerable supplements. Supplements are also sometimes given for trains that are scheduled to stop at a platform which is not on the main track, because this takes slightly longer to get to, and because engineering works are being done on the track, requiring lower speeds for part of the journey. These are meant to correct cases where the runtime calculation is known to be wrong; however they are not really margins increasing the robustness.

Headways, the time separation between trains going in the same direction on the same track, are another important way to provide robustness. A short separation implies a 
TABLE 1: Prioritization criteria for passenger trains and their associations, with social cost estimates. Reproduced from Appendix $4 \mathrm{~B}$ in the Swedish Network Statement for 2017 [23]. When alternative timetable solutions are compared to one another, the solution with the lowest total social cost estimate should be chosen. This entails first calculating the social cost for each train, using the estimates above value travel time, travel distance, phasing time (shifting departures from the times requested by the train operating companies), and associations between trains for both passengers and vehicles and then summing up the social cost across all trains in the timetable scenario. The cost estimates for rejected requests, trains that are not allowed to run in the timetable alternative, are estimated using a slightly different methodology outlined briefly in Section 2.1.1. Similarly, there is a threshold at which point an association is no longer considered viable, and instead of basing the cost on the time used, a fixed penalty is applied, as indicated in the column SEK/Assn. The train operating companies are required to (accurately, to the best of their knowledge) report the prioritization category of each of their trains along with the request for capacity, based on the identification criteria, and the computation of the social cost estimate is then done in Trainplan for each timetable scenario. Guidelines are also provided for how to handle new train concepts, where there is no previous knowledge of the number and type of passengers.

\begin{tabular}{|c|c|c|c|c|c|c|c|}
\hline \multirow[b]{2}{*}{$\begin{array}{l}\text { Description of } \\
\text { category }\end{array}$} & \multicolumn{4}{|c|}{ Identification criteria for prioritization categories } & \multicolumn{3}{|c|}{ Social cost estimate } \\
\hline & $\begin{array}{l}\text { Number of } \\
\text { passengers }\end{array}$ & $\begin{array}{c}\text { Share of time } \\
\text { sensitive } \\
\text { passengers }\end{array}$ & $\begin{array}{l}\text { Share of } \\
\text { regional } \\
\text { passengers }\end{array}$ & $\begin{array}{l}\text { Demand for } \\
\text { high speed, few } \\
\text { stops }\end{array}$ & $\begin{array}{l}\mathrm{SEK} / \mathrm{min} \\
\text { transport time }\end{array}$ & $\begin{array}{c}\text { SEK/km } \\
\text { transport } \\
\text { distance }\end{array}$ & $\begin{array}{c}\mathrm{SEK} / \mathrm{min} \\
\text { phasing time }\end{array}$ \\
\hline Heavy commuter & $\geq 700$ & $\geq 75 \%$ & $\geq 75 \%$ & & 1,150 & 93 & 784 \\
\hline Regio-commuter & $\geq 300$ & $\geq 75 \%$ & $\geq 75 \%$ & & 736 & 93 & 474 \\
\hline Regio-commuter & $\geq 300$ & $\geq 75 \%$ & $\geq 75 \%$ & & 736 & 93 & 474 \\
\hline Regio-max & $\geq 200$ & $\geq 75 \%$ & $\geq 75 \%$ & & 499 & 76 & 212 \\
\hline Regio-max & $\geq 75$ & $\geq 75 \%$ & & High & 499 & 76 & 212 \\
\hline Regio-standard & $\geq 75$ & $\geq 75 \%$ & $\geq 75 \%$ & & 240 & 27 & 132 \\
\hline Regio-standard & $\geq 25$ & $\geq 25 \%$ & & High & 240 & 27 & 132 \\
\hline Regio-low & $\geq 25$ & $\geq 75 \%$ & $\geq 75 \%$ & & 170 & 29 & 96 \\
\hline Regio-low & $\geq 75$ & & $\geq 25 \%$ & & 170 & 29 & 96 \\
\hline Regio-low & $\geq 25$ & & $\geq 25 \%$ & & 170 & 29 & 96 \\
\hline Regio-mini & $\geq 0$ & & $\geq 25 \%$ & & 46 & 22 & 10 \\
\hline IC-express & $\geq 200$ & $\geq 75 \%$ & & High & 753 & 64 & 429 \\
\hline IC-standard & $\geq 75$ & $\geq 25 \%$ & & & 484 & 41 & 291 \\
\hline IC-low & $\geq 25$ & $\geq 25 \%$ & & & 253 & 38 & 125 \\
\hline IC-low & $\geq 75$ & & & & 253 & 38 & 125 \\
\hline IC-mini & $\geq 0$ & & & & 80 & 15 & 31 \\
\hline IC-mini & $\geq 0$ & & & & 80 & 15 & 31 \\
\hline Unspecified & & & & & 35 & 11 & 8 \\
\hline Association & Passengers & & & & $\mathrm{SEK} / \mathrm{min}$ & SEK/Assn. & \\
\hline Conn. pas. max & $\geq 125$ & & & & 647 & 55,300 & \\
\hline Conn. pas. high & $\geq 75$ & & & & 304 & 26,000 & \\
\hline Conn. pas. std. & $\geq 50$ & & & & 190 & 16,300 & \\
\hline Conn. pas. low & $\geq 20$ & & & & 107 & 9,110 & \\
\hline Conn. pas. mini & $\geq 0$ & & & & 30 & 2,600 & \\
\hline Turnaround high & & & & & 0 & 37,300 & \\
\hline Turnaround std. & & & & & 0 & 19,300 & \\
\hline Turnaround low & & & & & 0 & 11,800 & \\
\hline
\end{tabular}

high capacity and throughput but also increases the risk that delays spread from train to train. In Sweden, minimum headways are regulated in a document [51], varying from two to seven minutes, depending on the location. The normal range, applying to most of the network, is from three to five minutes. It is unclear from the documentation to what extent this is a technical minimum and what has been added to improve robustness, but if headways are higher than required by the regulations, robustness would be expected to improve.
The third key factor for robustness of timetables is dwell time. If a dwell time is too short, the departure of the train will be delayed. Correspondingly, if the scheduled dwell time is longer than required for the exchange of passengers or goods, the excess time can be used to make up for any previous delays. The guidelines [52] state that dwell times for passenger trains should, in general, be two minutes long. Sometimes longer times are required and other times, if the number of passengers is small and the train and station are prepared for 
TABLE 2: Timetable planning standards for passenger trains in Sweden.

\begin{tabular}{lr}
\hline Robustness measure & Norm in the Swedish regulations \\
\hline Running time supplement & $+3 \%$ across the board, included in run time calculation \\
Node supplement & $3-4$ minutes per pair of nodes passed; 2 minutes if partial; \\
& $2-4$ nodes exist per railway line \\
Dwell time at stations & 2 minutes standard; 1 minute if the number of passengers is small \\
Minimum headway & $2-7$ minutes, most commonly 3-5 minutes \\
\hline
\end{tabular}

a speedier boarding process, one minute can be used instead. If the number of passengers is very small, it is possible to schedule a stop without dwell time, merely slowing the train down to a stop and then starting again immediately, but if this is done the runtime on the next line section should be extended, and if passenger numbers increase, the timetable should be redone and longer dwell times set.

The norms discussed above are summarised in Table 2. Vromans [53] compiled information on running time supplements used in the Netherlands, the United Kingdom, and Switzerland, and as required by the UIC which can be repeated here as a point of reference. While this information may appear dated, the timetabling norms have not changed significantly in Sweden since at least the 1990s, and there is reason to believe that the norms would be stable in other countries as well, even though the actual planning practice may well develop over time. According to Vromans [53], the Dutch use a running time supplement of approximately $7 \%$ across the board, for passenger trains. In the United Kingdom, runtime calculations are based on previous performance rather than physics-based methods, and the running time supplements are not explicitly defined [54]. The Swiss [55] use a supplement of 7\% for passenger trains, on top of which they add one minute for every 30 minutes of runtime and additional supplements in some locations, usually at highly utilised nodes. As a final point of comparison, the UIC [56] recommends a combination of time and distance based supplements: between three and seven percentage points are added to the running time, to which one should add between one and one and a half minutes for every $100 \mathrm{~km}$. Unfortunately, we have not found any norms or standards with regard to dwell times or headway times in other countries.

The complexity of traffic, changing conditions, and sheer number of decisions makes it difficult for planners to foresee the punctuality effects of individual decisions on the size and distribution of margins, headways, and dwell times. Because of this difficulty, there has not been a convergence around best practice in timetabling in Sweden, and there has not been a steady improvement in punctuality [1], which one might expect if planners were able to learn what works and what does not. Nonetheless, there has been a significant drift from the norms in how the timetables are scheduled in practice [49], as the running time supplements are routinely much larger in practice than in the norms, while the dwell times are significantly shorter.

2.1.3. Tools. The Swedish Transport Administration currently uses the tool Trainplan to create timetables, a tool which is also used in the UK railways [14] and is reviewed by Hammerton [57]. RailSys is increasingly being used to perform limited test runs of parts of the timetable using stochastic simulation, on a more detailed infrastructure model, and can address many of the issues presented in this paper. As in the UK, the group of trained users is small and used only as a complement to the main planning process. These software packages, their use, and their limits are discussed in depth by Watson [14]. One of the most important constraints is that Trainplan does not provide automatic conflict detection, meaning that the planners must check for these manually. As each planner plans for thousands or tens of thousands of trains per year, this is a recurring issue. New tools and processes, intended to improve the quality and efficiency of the timetable process roughly along the lines discussed in ONTIME [21], are under development at the Swedish Transport Administration and are to be rolled out gradually from 2018 through 2020.

With the introduction of information technology and increasingly powerful computers, simulation is gaining an increasingly important role in the railways, both in practice at infrastructure managers and in academia. In the early 2000s researchers at the Royal Institute of Technology began to model the Swedish railways in the simulation software RailSys [58]. After several years, the Swedish Transport Administration began to use this model to perform simulations in different aspects of its practice. This is now an established part of the process, and parts of the annual timetable are run through simulations in several iterations before they are finalised. Larger engineering works are also simulated regularly in order to estimate the effects on train traffic and to make appropriate changes to the timetable. This is being developed further, so that alternate plans for engineering works can be tested against each other [59].

However, the team of capacity analysts who use RailSys is still quite small and they are organized as a group of experts, which is involved in many projects besides the annual timetable planning. The timetable planning is still done in Trainplan, and the test runs in Railsys are limited in both number and scope. Thus, while some of the errors produced in the planning process are identified and corrected, the workflow of the planners is not really affected and many of the errors still go unnoticed.

2.2. State of the Art in Sweden. As a way to utilise the infrastructure capacity more effectively, the Swedish Transport Administration is funding research for simulation and optimisation tools for timetabling and rescheduling. Some of this work is outlined here, to give an idea of the research and development underway in Sweden, without intending to 
give a comprehensive review. This work creates an important and interesting backdrop to the ongoing development and impending implementation of new tools and processes for timetable planning.

2.2.1. The Capacity Allocation Process. The capacity allocation process itself, the framework for timetable planning, is also being developed and improved spearheaded by researchers at the Swedish Institute for Computer Science. A summary and roadmap toward implementation is presented in Aronsson et al. [60]. The background for this is twofold. One issue is that, with deregulation and the existence of multiple, competing train operating companies, the demands put upon the capacity allocation process are fundamentally different than before. Kreuger et al. [61] list some typical requirements from train operating companies and their customers, and based on these they developed a mathematical framework for detecting and resolving conflicts. The other issue is that the current allocation process has very long lead times, is inflexible, and leads to an inefficient capacity utilisation of the infrastructure. This is described by Forsgren et al. [62], who found several mathematical opportunities and challenges following an alternative process, where the decision-making is postponed as far as possible into the future.

Gestrelius et al. [63] developed an outline for a more efficient capacity allocation process. In the current process, train paths are made and used for the entire year. Once finalised, they are not allowed to be modified; they must instead be cancelled and replaced by a new train path in the ad hoc-process, which is not allowed to disturb the surrounding train paths. This often leads to, for instance, a train stopping at a certain station every day of the week, to await a meeting train that only runs on Tuesdays. All other days of the week, these scheduled stops are entirely unnecessary. The suggestion for the new process is to only lock down certain key characteristics of train paths, such as departure times from some important stations, retaining greater flexibility in later planning, and operational stages without compromising the quality of the train paths.

Gestrelius et al. [63] also present a method to generate these key characteristics based on an annual timetable, using rolling horizon planning and a mixed integer programming model, which optimises the train paths for each individual day, using different delivery commitments for different operators. They then applied the model on a case study in Sweden and showed that this allows for a more efficient utilisation of the infrastructure. Aronsson et al. [64] continued this work by working to estimate the value of this uncovered capacity, showing that a large portion of the available capacity is hidden when using the current planning methods and scheduling rules.

Working further on improving the process, Svedberg et al. [65] developed a model to optimise the welfare cost of different timetable variants, containing competing train operators, and they applied the model to a part of the Swedish rail network. A model like this gives the infrastructure manager a more correct and transparent way to rule on which trains should get their requested timetables and which should be adjusted or excluded. This is increasingly important as the number of requested train paths is increasing, and especially as the requests are coming from competing actors. The welfare cost derived from this framework can also be used to find the optimal number of departures, find the best departure times, and estimate the economic value of different timetable variants.

2.2.2. Robust Timetables. One line of research is directed at creating timetables that are robust against minor disturbances. An important prerequisite is developing methods on how to measure and quantify this robustness, ideally before the timetables are put into operation. Andersson et al. [66] show that there is a clear mismatch between where margins are placed and where delays occur. They also suggest that punctuality should be measured at all stops, not only the final destination. Peterson [67] studied two Swedish train services, finding that dwell times are usually underestimated and not sufficiently compensated by margins on the line and that the precision of the train paths decreases linearly with the running time. Building on this finding, Khoshniyat and Peterson [68] modified timetables so that the assigned minimum time slot in the train path is increased linearly with the service's travel time. Based on numerical experiments on a double track segment of the Swedish Southern Mainline, they conclude that the modified timetables perform better when small disturbances are introduced.

Several new ex ante robustness measures have been proposed. Gestrelius et al. [69] propose that the number of possible alternative meeting locations between two trains is a robustness measure, as it gives flexibility for rescheduling. Khoshniyat [70] developed a headway-based method, which can improve robustness without imposing major changes in timetables, and proposes four new measures: Channel Width, Channel Width Forward, Channel Width Behind, and Track Switching. Andersson et al. [71] also propose a new robustness measure: Robustness in Critical Points (RCP), which is focused on points in the timetable that are particularly sensitive to delays. Warg and Bohlin [72] established a timetable performance index to evaluate the benefits and robustness of a timetable from a passenger perspective, by combining simulation and socioeconomic analyses.

Once robustness measures have been proposed, it is possible to optimise timetables around them. For instance, Andersson et al. [73] propose a model which reallocates existing margin time to increase the RCP. This is tested by simulation runs of an initial timetable and one with reassigned margins, while introducing small delays. In the adjusted case, total delays at the end station are $28 \%$ lower. Solinen et al. [74] also use an optimisation model to increase the RCP throughout a timetable and evaluate the results with simulation. They found that robustness increased locally, but that the relationship between ex post measures and RCP must be studied further.

2.2.3. Tools. One prototype tool based on optimisation, which has been developed and evaluated, is called the Maraca [75]. It is used for nonperiodic timetabling and minimises resource conflicts, thus enabling the user to focus on the 
strategic decisions. Based on a trial of this prototype, Forsgren et al. [76] show how computer and optimisation based tools can provide valuable insights, even before full-scale implementation. Another tool, intended for marshalling yards, is designed by Gestrelius et al. [77] who design an integer programming model to schedule shunting tasks and to allocate tracks in both the arrival yard and the classification bowl. This tool has a planning period of four days and optimises characteristics like shunting work effort, the number or cost of tracks, and the shunting task start times.

Similarly, the rescheduling of trains in disturbed scenarios is amenable to methods and tools using optimisation. Krasemann [78] developed an algorithm, which effectively delivers good solutions within the permitted time, performing a depth-first search using an evaluation function to prioritize when conflicts arise, and then branches according to a set of criteria. Krasemann [79] then shows that the approach is feasible for practical problems, using the case of the Iron Ore Line in Northern Sweden and solving many different delay scenarios to optimality within one minute or less.

\section{Methodology}

To produce the material for this paper, we carried out semistructured interviews with timetable planners working at the Swedish Transportation Administration's office in Malmö. Each interview was approximately an hour long, recorded, and transcribed in full, which resulted in a written material of around 50 pages. The results were analysed by manual categorisation and concentration of meaning.

The Swedish Transport Administration employs about 20 long term timetable planners, who work chiefly in the annual timetabling process. In addition to these, there are shortterm timetable planners who work in the ad hoc-process. The Swedish railway is divided into eight regions, and the southernmost region is planned from the office in Malmö by four timetable planners, all of whom we interviewed. Two of the planners were men and two women. All of them have worked in the industry for many years, at least since 2003 and going back as far as 1985, and with timetables for nine or more years.

This region is a sort of microcosm of the railway network in Sweden, and it contains a very diverse mix of railway lines, train traffic, and capacity utilisation. It includes the Southern Mainline, one of the most heavily used in the country, dense commuter systems around Malmö-Lund-Helsingborg, heavy freight traffic mixed with passenger trains on the singletrack Scania Line, sparser passenger traffic around Ystad, Karlskrona, and Kalmar, and several nonelectrified lines with local, manual train dispatching and very low traffic volumes. Thus, while we have only interviewed planners in one region, those planners have been exposed to a wide variety of planning conditions and circumstances.

We used a qualitative method because this allowed us to effectively study the values and priorities of those involved. In this choice of method, we thus applied a qualitative approach on a topic that is typically studied using quantitative methods. We prepared an interview guide based on four areas which were identified before the interviews: (1) guidelines and support, (2) rules of thumb, (3) feedback loops, and (4) tradeoffs, with a handful of guiding questions in each area.

The process of analysing the transcribed material was carried out in sequence. The first step was to sort the different interviewer-interviewee exchanges by area, rather than by chronology, what Kvale [80] and Hammersley and Atkinson [81] call categorisation. The second step was to concentrate the meaning of the answers [80] by cutting superfluous words and sometimes reformulating entire paragraphs into a few sentences. This was a necessary process, to make it feasible to get an overview of what was said, and the volume of text was reduced from 24,500 words to only 4,500. All these steps were performed manually.

The following has been translated from Swedish and provides an example of the concentration of meaning:

\begin{abstract}
The transcript
"Unfortunately, the time is short, so we don't have time to quality control ourselves, rather it's like: now I've done that train I hope it's right. We have two occasions where Traffic Control go in and check, but they can't see everything either. So unfortunately, we can't do the kind of quality of work that we would like because the resources aren't enough, we have to focus on getting it done."

can be condensed to

"We focus on getting it done, and don't have time for quality control. The Traffic Control try to check, but can't see everything."
\end{abstract}

Having concentrated the interview answers, we made a more detailed sorting, and 16 new subareas were identified. Following this, we further summarised the contents, reducing the volume from 4,500 to 500 words. This made it manageable to get an overview of the contents. Section 4 contains translations of these summaries, grouped into the four areas of the interview guide. An example of this second step of summarising

"Traffic Control gives daily feedback: insufficient meeting time, crossing train paths, stopped freight train before a slop, train stops on the wrong track."

"Feedback: want the train on another track, crossing train paths, infeasible timetable. Adjust in ad hoctimetable and in dialogue with train operating company, but not always possible."

"Traffic control usually tells us: trains are too long, or always late. Less feedback about punctuality, but there can be problems around engineering works or ad hoctrains that only run a single day and make a mess. We mostly focus on the train numbers that run more often."

"A new group is looking at the code 'suspected error in the timetable', finding new errors: shouldn't have a meeting with zero dwell time in Mörrum [a small station], because then the trains lose two minutes." 
"Easy to miss crossing train paths, because our systems lack conflict management. You learn after a while how to handle different locations, but it's not written down anywhere."

can be summarised into

"Traffic control has a lot of feedback. Short meeting times, crossing train paths, bad track allocation, trains that are too long, and freight trains stopped in slopes."

The analysis in Section 5 is based on an alternate reading of the interview responses. We identified instances in the interviews where the planners described feedback from traffic control about errors in the timetable, which can be seen in the examples of translated and concentrated statements provided above, and we focused on the ones that were mentioned most frequently among the planners. We also identified several statements that could explain why errors sometimes occur in the timetable and condensed these into a list of eleven reasons. At this point, we looked for different ways to group and categorise the answers, looking for themes on a higher analytical level, and came up with the three following categories, which we use in the analysis: (1) "missing tools and support," (2) "role conflict," and (3) "single-loop learning" (see Argyris and Schön [30] and Section 2 above). These three categories are used to explain and discuss the reasons behind the errors more deeply.

\section{Results}

The questions in the interview guide were structured around four areas, and we will begin by reporting summaries of the responses according to each area. These summaries add to the contextual understanding of the timetable planning in Sweden and document issues in ways that could not be achieved by studying documents or guidelines and are a key part in establishing a baseline for later evaluations and studies, following the implementation of the new tools and processes. Further analysis and discussion of interview responses follows in Sections 5 and 6.

4.1. Learning and Feedback Loops. The planners explained that the timetabling work is split by lines, with some muchneeded reinforcement at large stations. They state that they have a large individual responsibility, both in learning what is necessary and in performing quality control, that it takes a long time to learn the details of each railway line, and that there is no time for quality control. It is difficult to transfer accumulated experience. Even though there is some education and transfer of knowledge as a line is handed over, it is insufficient and quite short. The planning method has been largely the same for the last 20 years or so, but the work is continuously getting more difficult, due to the increasing number of trains and engineering works. Problems increasingly occur at the stations, where the capacity is insufficient. In the past, the reverse used to be true.

There is no systematic evaluation or quality control: it is up to the individual planners, and they do not have time to perform it. The feedback loop that exists is from operational traffic control, most frequently about insufficient meeting times, crossing train paths, poor track allocation, trains that are too long for the allocated tracks, and freight trains being stopped at inclines. However, there is no established system or routine to keep track of these comments, or to make use of them, other than making a note mentally or on paper and trying to remember this information until it can be used next year. The planners also feel that important preconditions change from year to year, which makes it difficult to draw comparisons and lessons between years, making it even more difficult to make use of the loose notes that they make based on the feedback.

4.2. Support and Guidelines. The planners describe a somewhat contradictory experience of the work environment: the women describe the atmosphere as open and helpful, while the male planners describe a lonelier experience. The more experienced planners work more based on discussions with the train operating companies than on a strict application of the guidelines. The one who was newest at the job and who had more often switched between railway lines stressed the importance of studying the geography and signalling systems extensively. The guideline document [52] was mentioned by all the interviewees, but it is interpreted liberally and was not described as helpful. A new version is said to be coming soon, but this has been said for several years. Trainplan is the main tool and while it does many things, the version used at the Swedish Transport Administration does not handle track allocation, manage conflicts, or provide topographical information. The train operating companies often agree among themselves and apply detailed timetables. The planner only adjusts when necessary, and this is done in dialogue with the train operating companies. As a planner, one must know which signal-box models are present and how they work, which is quite complicated without sufficient technical support.

4.3. Trade-Offs. Although the timetable planners know that trains are sometimes late, they report that they cannot plan a timetable based on the trains running late. Engineering works that move along the line during the year are difficult to schedule properly, as the location for the delay shifts over time. Creating new train paths for each scenario is challenging and discouraged by the capacity allocation process. The lack of capacity, especially at stations, is mentioned by several interviewees as the most difficult problem in their work. It appears to be a bottleneck-problem, rather than one of sheer volume, where past a certain threshold it becomes very difficult. The planners try to handle the lack of capacity in dialogue with the train operating companies, and they all describe different principles for doing so. The problem of congestion is exacerbated by the short-term planners bending the rules to fit in more trains. Negative margins are often used for local trains on single-track, so that the scheduled runtime is shorter than the calculated minimum runtime, at the request of train operating companies. The explanations for this vary from person to person, but the planners state that "it has always been like this." 
4.4. Rules of Thumb. The planners express that node supplements are the primary way of assigning margins, but everyone describes a different methodology for assigning them. Some give descriptions that seem to run counter to the few rules that are written down. Another very common practice is to adjust arrival and departure times at control points so that they occur at whole minutes. At some places, this is described as required for technical reasons, but it appears popular even elsewhere. Usually, seconds are added up to the whole minute but sometimes subtracted. Phasing supplements are an important tool to make the timetables feasible. Only the most experienced planner adds a minute after a scheduled stop, as per an old unwritten rule going back decades, although others were aware of the practice. The train operating companies generally set the dwell times. The planners say that the standard is two minutes, but they give the impression that shorter times dominate. Local trains are often given the same arrival and departure times, with no scheduled dwell time, to avoid waiting unnecessarily in case the train is delayed or the number of passengers is small. Dwell times in excess of two minutes are primary for connections and phasing reasons and in rare cases for trains going into the mountains during holidays, when many people bring skis and similar equipment.

\section{Analysis}

Here we present the results of an alternate reading of the responses, focusing on the errors that occur in timetable planning, the reasons behind them, and three themes running through these reasons.

The Swedish timetable planners described receiving daily feedback from traffic control; see the excerpts in Section 3, which are primarily centred on four areas: (a) crossing train paths at stations, (b) wrong track allocation of trains at stations, especially long trains, (c) insufficient dwell and meet times at stations, and (d) insufficient headways leading to delays spreading. To give a rough idea of the relative frequency of these errors, throughout the transcripts the planners explicitly mention receiving feedback relating to (a) five times, (b) nine times, (c) six times, and (d) twice. The issue of crossing train paths is mentioned frequently as a difficult issue: 15 times throughout the transcripts, suggesting that the planners are working hard on finding and eliminating such errors, with partial success.

Based on the interviews, we have also identified eleven reasons why the timetables sometimes lack quality, allowing the occurrence of errors. These reasons were not explicitly stated or described as such but were identified by reading and sorting through the transcripts. We have also identified three common themes that run through the list: "missing tools and support," "role conflict," and "single- rather than double-loop learning" (trying to follow the established norms rather than trying to establish the right norms, see Argyris and Schön [30]). This is all summarised in Table 3.

The leftmost column in Table 3 contains an identifying number, used in the following sections. The second column from the left describes the reason for lacking quality, and the centremost column identifies which of the four common errors (a)-(d) is associated with this reason. These four errors are discussed further in the table text. The three rightmost columns illustrate how the eleven reasons map onto the three themes we have identified. Each of these themes are discussed in the following sections.

5.1. Missing Tools and Support. One theme running through the responses is that the proper tools to perform timetable planning are missing. This is most clearly illustrated by reasons (2)-(5) in Table 3. Based on the answers given, such tools would free up time and allow a shift in focus from the details to quality assurance and a better overview of the timetable. The planners state that they must keep track of which model of signalling control is present at each location and how it works. This is complicated and the planners described that there is very little support available.

The main tool used by the planners in Sweden also lacks functions for track planning and conflict management and does not provide topographical information. These functions were intended to be part of the current software tool, when it was procured in the early 2000s, but the implementation of these modules was cancelled, allegedly because the quality of infrastructure data was too poor. New tools for both planning and control of traffic are under development, and the planners hope that these important functions will be implemented in the coming years.

The guiding document for timetable planning was mentioned by all four planners but was not very helpful and is interpreted liberally. A new version is said to be arriving soon, but this has been said for several years. The planners also state that the problem of insufficient capacity is worsened by operational timetable planners being less rigorous in following the guiding documents, when inserting new trains into the gaps that do exist.

5.2. Role Conflict. Another underlying theme is the inherent role conflict of timetable planners, which is best illustrated by reasons (6)-(9) in Table 3; an overly liberal interpretation of the planning rules and guidelines is that train operating companies ask for shortcuts to fit more trains into the timetable, that train operating companies request short dwell times to avoid trains waiting, and that there is no clear strategy for the location and size of time supplements.

One example of this conflict is how the decision to deny a train request, because of capacity constraints, is described as difficult and controversial. Denied requests can be, and often are, challenged through the formal capacity allocation process described in Section 2.1.1, which leads to a lengthy and difficult legal process of showing that everything was done correctly and transparently. Producing a timetable, which cannot in practice be executed as scheduled, and which is likely to cause delays, is not subject to the same formal procedures or complaints.

Another example is how the more experienced planners focus more on discussions aimed at reaching a consensus with the train operating companies than on a strict application of the guidelines. In Sweden, the train operating companies mostly agree between themselves and apply with detailed timetables, which the planners only adjust when necessary 
TABLE 3: Reasons why errors occur in timetables. The four types of associated errors are (a) crossing train paths at stations, (b) wrong track allocation of trains at stations, especially long trains, (c) insufficient dwell and meet times at stations, and (d) insufficient headways leading to delays spreading. (a)-(b) make the timetable infeasible without intervention from traffic control, are therefore considered the most critical, and can be described as inadvertent mistakes. (c)-(d) systematically lead to delays occurring, increasing, and spreading and are made intentionally to accommodate the train operating companies, even if the consequences are not fully understood. Note the high extent to which these errors are focused around stations.

\begin{tabular}{|c|c|c|c|c|c|}
\hline Number & Reason for lacking quality, description & $\begin{array}{l}\text { Associated } \\
\text { errors }\end{array}$ & $\begin{array}{l}\text { Theme } 1 . \\
\text { Missing tools } \\
\text { and support }\end{array}$ & $\begin{array}{c}\text { Theme } 2 \text {. Role } \\
\text { conflict }\end{array}$ & $\begin{array}{c}\text { Theme } 3 . \\
\text { Single- rather than } \\
\text { double-loop learning }\end{array}$ \\
\hline
\end{tabular}
(1) Insufficient time for quality assurance of
timetables

Too many issues to keep in mind manually for planners
(a), (b),

(c), and

(a), (b) $\quad \mathrm{X}$

Work is becoming more difficult due to increasing congestion

(a), (b)

(a), (b),

(c), and

(d)

Congestion on st
complex stations

Missing tools for track allocation and conflict management

(a), (b)

(c), (d) guidelines

Train operating companies ask for shortcuts to fit more trains into the timetable

(c), (d)

(c) times to avoid trains waiting

No clear strategy for the location and size of time supplements

(c), (d)

Poor feedback and evaluation of timetables; no routine for continuous improvement

(a), (b),

(c), and

(d)

Poor knowledge transfer to new planners; poor documentation (a), (b),

(c), and

(d)
X

$\mathrm{X}$

$\mathrm{X}$

$\mathrm{X}$

$\mathrm{X}$

$\mathrm{X}$

$\mathrm{X}$

$\mathrm{X}$

$\mathrm{X}$ and then in dialogue with the companies, doing what they can to squeeze the trains in. For instance, insufficient dwell times and negative margins are often given to local trains on single tracks, on request from the train operating companies. The rationale for this differs from planner to planner, but "it has always been done like this."

5.3. Single-Loop Learning. The last theme is best illustrated by reasons (1)-(2) and (9)-(11) in Table 3 and refers to the concept described in Argyris and Schön [30] and Section 2. The timetable planners have a large amount of individual responsibility: in the number of timetables that they must create, in learning the relevant signalling control systems, in applying the rules and guidelines, in assigning margins, in creating robustness, and in controlling the quality. They show that it takes a long time to learn the geography and that there is no time for quality control. The task gets harder and harder because the number of trains and engineering works are increasing.

There is no systematic evaluation. This is up to each planner, and they say that they do not have the time. Important preconditions change from year to year, which makes it difficult to compare between different timetables and to transfer the notes made about feedback and errors from one year to the next one. This contributes to the conditions described in ONTIME [21, p. 37] which also commented on the timetabling process in Sweden: "the accumulated knowhow of train dispatchers and train drivers is not fed back to the timetable construction process to any larger extent." It is also difficult to transfer accumulated experience: even though there is some education and transfer of knowledge to new planners, it is described as insufficient and too short.

The planning work in Sweden is centred on finishing the timetables in time, while keeping in mind all the technical details and constraints of different signalling control systems and rolling stock, the topography, crossing train paths, track allocation, and so on. This is a direct parallel to the situation in the UK described by Watson [14, p. 112], where "achieve all timetable production timescales" is listed as the number one priority among timetable planners at Network Rail and "error free" only as number six, in a ranked list of eight priorities. The British timetable planners that Watson [20, p. 312] interviewed primarily requested "help with elimination or reduction of the repetitive data manipulation tasks that 
delay them from tackling the 'interesting' conflict resolution and resource minimisation work.”

The lack of support and proper tools means that there simply is not enough time or energy left to assess whether the rules and guidelines are the best or most appropriate ones to use. There is not enough time to consider what would make the timetable better, or to ensure that the errors from previous years are not repeated. If the implementation of new tools can help to streamline the workflow for timetable planners, the planners could use more of their time considering how to make the timetable better and more robust.

\section{Discussion}

This paper is focused on how the timetable process and the decisions of timetable planners contribute to delays and nonpunctuality. Timetable properties have been shown to be important and that changes to the timetable are relatively easy, quick, and inexpensive to make, in comparison to changes to infrastructure, rolling stock, and maintenance practices. While we show that timetable planners make errors that lead to delays, we do not suggest that this is the most important contributor to delays overall.

It is also important to distinguish between what timetable planners do, which contributes to nonpunctuality, and what they do to contribute to punctuality. In the interviews, it is made clear that planners are really struggling to create a feasible, error-free timetable and that they need more assistance. Before this is addressed, there is no time left in the process for them to increase robustness. There is clearly a need for tools to help generate and prove feasible timetables more quickly. Once the planners have these tools they can focus on improving the robustness.

The importance of new tools directed at helping generate timetables more quickly and verifying that they are feasible and error-free is also evident from the interviews. As these new tools and processes are being developed and implemented, it is interesting to consider and discuss the role of timetable planners in the future. One viewpoint that is often raised is that the planners will go from drawing timetables to monitoring the systems that draw them. The focus will shift from creating a timetable, to creating a better timetable. However, the current system already assumes that this is the case. The results of this paper suggest that planners are already entrusted with a large degree of discretion and are solely responsible for creating good, robust timetables. The problem is that they currently do not have the means to meet that responsibility, because the task of creating $a$ timetable is too demanding and time-consuming. If provided with better tools and support and if the feedback loops were improved, it would be possible for the planners to rise to the challenge in the future. As is, they do not appear to be anxious or worried that they will lose their jobs to automation: the impression is perhaps more of frustration that the tools do not work as they should.

Conflicting train paths, track allocation, and constraints due to different signalling control systems could all be handled well through software, but the tools currently used do not do this. As new tools and routines are implemented, it is important to ensure that these important functions are included and that enough high quality data is provided for the systems. While the role conflict cannot be entirely avoided by technology, new tools and processes can diminish the consequences by no longer permitting things such as negative margins and very short dwell times. Thus, more egregious errors could, perhaps, be eliminated. The planners would then also have more support when denying some requests from the train operating companies, but this support could be given in other, less technical ways. Adjusting the penalty associated with excluding trains, which is severe and lacking any theoretical basis, would be one such measure that could easily be implemented on a policy level.

It would also be helpful to clarify the roles and responsibilities between the different parties. With a separation between the infrastructure manager and the train operating companies, it is conceivable that both parties would like to assume responsibility for ensuring that the timetable has a high quality. The train operating companies might want to be responsible, because timetables are core part of their business with significant impacts on their customers' experience. The case is also strong for the infrastructure manager to assume responsibility, because it needs to coordinate traffic from many different companies, as well as engineering works. However, the results of this paper indicate that neither party assumes the responsibility. Clarifying the roles by clearly stating which party is responsible for the quality and robustness of the timetable would help make this interaction more constructive.

The results presented in this paper suggest that both researchers and practitioners should focus more on identifying and improving the relevant feedback loops, to achieve a higher level of learning among those involved. Single-loop learning is both a technical and organizational issue. Since the tools are lacking, planners are hard-pressed merely to finish their work. The time is simply not sufficient to perform quality control. Because there is no systematic review of the quality and outcome, there is no way to begin to improve the rules and guidelines, or to create a better timetable. This supports the findings in Watson [14], Hellström [19], and ONTIME [21]. As the tools do not provide enough assistance, the focus is, and must be, on creating a timetable before creating a better timetable. Creating a better timetable is what we imagine the timetable planners of the future will be tasked with doing, when more of the work has been automated and the software tools provide far more assistance. Rather than trying to manually execute all the details, they will choose which heuristics, goal-functions, and constraints to apply in different scenarios to achieve the best overall results.

This study focuses on Sweden. In the literature, we have seen large similarities with the United Kingdom, which uses the same tools and has a similarly deregulated market. The new tools that are currently being implemented in Sweden have recently been implemented, by the same supplier, in both Norway and Denmark. Experts from the infrastructure manager and largest train operator in the Netherlands [82] describe similar issues with errors causing delays and infeasibility there. We believe that the planning process is largely similar across most European countries, although 
the level of deregulation and competition between train operating companies for capacity may vary, as will the tools and contexts.

Reflecting on the methodology, we found it very rewarding to interview the people involved in the actual work of planning in a structured way, and we found them to be surprisingly frank and forthcoming. We are also pleased with how much more information can be extracted from the interviews when the transcripts are concentrated, categorised, and sorted. It is a very time-consuming process, but in our experience, it makes the initial investment of conducting and transcribing the interviews even more worthwhile. Being able to query the transcribed material from different angles, rather than being bound by the initial structure provided by the interview guide, is also very valuable and one of the key methodological takeaways for us.

As a final note, the findings in this study have been reported to both managers and experts at the Swedish Transport Administration on several occasions. They have expressed a keen interest in the research, in its results, and in spreading the findings deeper into the organization and the planning process. The problems with the current set of software are well known internally, which is one of the reasons for the large and currently ongoing project of replacing it. More surprise has been expressed on the theme of role conflict, in the perceived lack of internal support for timetable planners to go against the wishes of the train operating companies, for the benefit of the overall timetable. The managers realise that this is a question of leadership, where they can and must improve. The issues around learning and feedback also generated extensive interest and discussion on the role of timetable planners in the future once the software provides better support and on how to more systematically implement methods and routines for continuous learning and improvement.

\section{Conclusions}

The process of timetable planning in Sweden has been mostly stable since the beginning of the new millennium, with only minor changes in the processes, norms, and tools used. Over the next few years this will change, following a very significant investment in developing new tools and routines. The large shift that this is brought about presents a rare opportunity to study a major transition in timetable planning. Any large investment like this should be evaluated seriously, to assess the effects and draw lessons for the future. This paper helps establish the baseline for such an evaluation. Finally, a growing research interest into robust timetables, for more punctual train traffic, also justifies studying the timetable planners and process.

Studying the Network Statements of European railways, we found that the processes are largely similar; the difference is mainly in how to prioritize when two or more train operating companies have requested the same train slot. Whereas Sweden uses social cost estimates based on the theory of welfare economics, the British use a more qualitative assessment based on eleven predefined criteria; Germany selects the train that would pay the highest track charges, while the Dutch successively raise the track charges for the conflicting trains until only one party is willing to run the train.

Based on interviews with timetable planners in Sweden, we found that errors in timetables commonly lead to infeasible timetables, which necessitate intervention by traffic control, and to delays occurring, increasing, and spreading. The errors we identified are (a) crossing train paths at stations, (b) wrong track allocation of trains at stations, especially for long trains, (c) insufficient dwell and meet times at stations, and (d) insufficient headways leading to delays spreading. The situation is very reminiscent of the one described by Watson [14] in the UK, preceding our study by almost a decade: the timetable planners really struggle to create a timetable to begin with, and they do not manage to produce one without errors.

Reading through the transcripts of the interviews, we have identified eleven reasons for these errors, and running through these reasons, we have identified and discussed three themes: (1) missing tools and support, (2) role conflict, and (3) single-loop learning. The first theme, that proper tools and support are missing, is mostly a technical issue. The second theme is that of a role conflict for planners, which is mostly an organizational issue. On the one hand, they must strive to meet the demands of the train operating companies and, on the other hand, they must be unbiased and create a timetable that has a very high quality overall. The third theme is that planners, both individually and as a collective, appear to be stuck in single-loop learning [30], which is both a technical and organizational issue.

\section{Appendix}

\section{Interview Guide}

Note. The questions are translated from Swedish. Questions in italic were optional, intended to follow up.

\section{Introductory Questions}

Can you please tell me briefly about yourself and your background?

Can you please tell me briefly about how you work with the upcoming annual timetable?

\section{Questions on Feedback}

How long have you worked here?

Can you please tell me a little about what you have learned since you started working here?

Can you please talk briefly about how the work has changes since then?

Approximately how is the work divided between those of you who create the annual timetable?

Can you please give some examples of how you exchange knowledge and experiences, between colleagues? 
Can you please explain briefly how those of you who create the annual timetable evaluate it, after the fact?

Can you please give some examples of how you tie back to earlier timetables, coming into the annual timetable for 2017 ?

On what level of detail is this feedback done?

Can you please briefly state what the punctuality looks like on the lines, trains and stations you plan for?

\section{Questions on Guidelines}

Can you please tell me about the guidelines and support you have available when you create an annual timetable?

Can you please give an example of when you turned to the guidelines?

Can you please give an example of when you used "Olsson's minute"? [A running time supplement of one minute directly following a scheduled stop, named after a timetable planner working several decades ago]

Can you please give examples of where you allocate "node supplements"?

How often do you have to allocate supplements for trains using secondary tracks?

Can you please talk a little about what tools you use when creating a timetable?

Can you please give an example of how close you stick to the timetables applied for by the train operating companies?

How specific are the train operating companies' applications with regards to dwell times?

How binding are the train operating companies' applications with regards to dwell times?

How specific are the train operating companies' applications with regards to run times?

How binding are the train operating companies' applications with regards to run times?

How specific are the train operating companies' applications with regards to arrival times?

How binding are the train operating companies' applications with regards to arrival times?

\section{Questions on Rules of Thumb, Heuristics}

What do you typically use as a dwell time for passenger trains?

Can you please give examples of factors that contribute to your allocating a longer or shorter dwell time?

Can you please give examples of when you allocate a longer dwell time?

Can you please give examples of when you allocate a shorter dwell time?
What difference does the train type make?

What difference does the volume of passengers make?

What difference do the punctuality statistics make?

Can you please give an example of when margins are needed in a timetable?

If you believe they are required, where do you allocate the margins?

Can you please give examples of how you decide on the size of margins?

Can you please talk a little about which factors come into play here?

What difference does the location make?

What difference does the train type make?

What difference does the volume of passengers make?

What difference do the punctuality statistics make?

\section{Questions on the Trade-Offs in Timetable Planning}

Can you please talk a little about the trade-offs you make in your work, creating the annual timetable?

Can you please give some examples of difficult tradeoffs you have made recently?

Trade-offs between short and reliable journey times?

The trade-off between margins at stations or on the line?

The trade-off between concentrated and distributed margins?

Can you please give an example of where you willingly created a delay for a train?

\section{Disclosure}

This is an extended version of a paper presented at the 20th EURO Working Group on Transportation Meeting (EWGT2017) in Budapest, on 4-6 September 2017 [83].

\section{Conflicts of Interest}

The authors declare that there are no conflicts of interest regarding the publication of this paper.

\section{Acknowledgments}

The authors would like to thank the Swedish Transport Administration for providing funding for the research, as well as providing access to the interviewees and to the governing documentation. Finally, the authors also thank the project reference group for their continuous assistance, guidance, and feedback.

\section{References}

[1] Transport Analysis, Rail Traffic 2015, Transport Analysis, Stockholm, Sweden, 2016. 
[2] M. Grimm, Järnvägens kapacitetsutnyttjande 2016, Swedish Transport Administration, Borlänge, Sweden, 2017.

[3] Y. Xia, J. N. Van Ommeren, P. Rietveld, and W. Verhagen, "Railway infrastructure disturbances and train operator performance: The role of weather," Transportation Research Part D: Transport and Environment, vol. 18, no. 1, pp. 97-102, 2013.

[4] W. Brazil, A. White, M. Nogal, B. Caulfield, A. O'Connor, and C. Morton, "Weather and rail delays: Analysis of metropolitan rail in Dublin," Journal of Transport Geography, vol. 59, pp. 69-76, 2017.

[5] Y. Qin, X. Ma, and S. Jiang, "A Stochastic Process Approach for Modeling Arrival Delay in Train Operations," in Proceedings of the Transportation Research Board 96th Annual Meeting, 2017.

[6] M. F. Gorman, "Statistical estimation of railroad congestion delay," Transportation Research Part E: Logistics and Transportation Review, vol. 45, no. 3, pp. 446-456, 2009.

[7] N. O. E. Olsson and H. Haugland, "Influencing factors on train punctuality - Results from some Norwegian studies," Transport Policy, vol. 11, no. 4, pp. 387-397, 2004.

[8] N. Olsson, A. H. Halse, P. M. Hegglund et al., Punktlighet $i$ jernbanen - hvert sekund teller, SINTEF Akademisk Vorlag, Oslo, Norway, 2015.

[9] M. Veiseth, N. Olsson, and I. A. F. Saetermo, "Infrastructures influence on rail punctuality," WIT Transactions on The Built Environment, vol. 96, pp. 481-490, 2007.

[10] J. Parbo, O. A. Nielsen, and C. G. Prato, "Passenger Perspectives in Railway Timetabling: A Literature Review," Transport Reviews, vol. 36, no. 4, pp. 500-526, 2016.

[11] P. B. L. Wiggenraad, Alighting and boarding times of passengers at Dutch railway stations, TRAIL Research School, Delft, Netherlands, 2001.

[12] L. Nie and I. A. Hansen, "System analysis of train operations and track occupancy at railway stations," European Journal of Transport and Infrastructure Research, vol. 1, pp. 31-54, 2005.

[13] C. W. Palmqvist, N. O. E. Olsson, and L. Hiselius, "Delays for passenger trains on a regional railway line in Southern Sweden," International Journal of Transport Development and Integration, vol. 1, no. 3, pp. 421-431, 2017.

[14] R. Watson, Train Planning in A Fragmented Railway - A British Perspective, [Doctoral, thesis], Loughborough University, Loughborough, England, November 2008.

[15] A. Kauppi, J. Wikström, B. Sandblad, and A. W. Andersson, "Future train traffic control: Control by re-planning," Cognition, Technology \& Work, vol. 8, no. 1, pp. 50-56, 2006.

[16] S. Tschirner, B. Sandblad, and A. W. Andersson, "Solutions to the problem of inconsistent plans in railway traffic operation," Journal of Rail Transport Planning and Management, vol. 4, no. 4, pp. 87-97, 2014.

[17] B. Sandblad, A. W. Andersson, and S. Tschirner, "Information Systems for Cooperation in Operational Train Traffic Control," Procedia Manufacturing, vol. 3, pp. 2882-2888, 2015.

[18] E. M. Roth, N. Malsch, and J. Multer, "Understanding How Train Dispatchers Manage and Control Trains: Results of a Cognitive Task Analysis," DOT-VNTSC-FRA-98-3, National Technical Information Service, Springfield, VA, USA, 2001.

[19] P. Hellström, Problems in the Integration of Timetabling And Train Traffic Control, Uppsala University, Uppsala, Sweden, 2013.

[20] R. Watson, "Prospects for computer aided railway scheduling: Perspectives from users and parallels from mass transit," Transportation Planning and Technology, vol. 23, no. 4, pp. 303-321, 2000.
[21] ONTIME, Benchmark analysis, test and integration of timetable tools, Delft University of Technology, Delft, Netherlands, 2014.

[22] Swedish Transport Administration, Improved Capacity, 2017, Available at https://goo.gl/mVkSW6.

[23] Swedish Transport Administration, Network Statement 2017, Swedish Transport Administration, Borlänge, Sweden.

[24] I. A. Hansen and J. Pachl, Railway Timetabling \& Operations, Eurailpress, Hamburg, Germany, 2nd edition, 2014.

[25] F. Avelino, M. te Brömmelstroet, and G. Hulster, "The Politics of Timetable Planning: Comparing the Dutch to the Swiss," in Proceedings of the Colloquium Vervoersplanologisch Speurwerk 2006, pp. 23-24, Amsterdam, Netherlands, November 2006.

[26] D. Wood and S. Robertson, "Planning tomorrow's railway role of technology in infrastructure and timetable options evaluation," in Capacity Management Systems, Computers in Railways VIII, J. Allan, R. J. Hill, C. A. Brebbia et al., Eds., 2002.

[27] M. S. Feldman and B. T. Pentland, "Reconceptualizing organizational routines as a source of flexibility and change," Administrative Science Quarterly, vol. 48, no. 1, pp. 94-118, 2003.

[28] D. Kahneman, P. Slovic, and A. Tversky, Judgment Under Uncertainty: Heuristics and Biases, Cambridge University Press, New York, UK, 1982.

[29] M. Bazerman, Judgement in Managerial Decision Making, Wiley, New York, NY, USA, 4th edition, 1998.

[30] C. Argyris and D. A. Schön, Organizational learning II: theory, method, and practice, Addison-Wesley, Reading, Mass, USA, 1996.

[31] M. Loock and G. Hinnen, "Heuristics in organizations: A review and a research agenda," Journal of Business Research, vol. 68, no. 9, pp. 2027-2036, 2015.

[32] C. B. Bingham and K. M. Eisenhardt, "Rational heuristics: The 'simple rules' that strategists learn from process experience," Strategic Management Journal, vol. 32, no. 13, pp. 1437-1464, 2011.

[33] G. Kirkebøen, "Decision Behaviour - Improving Expert Judgement," in Making Essential Choices with Scant Information, T. M. Williams, K. Samset, and K. Sunnevåg, Eds., Chippenham and Eastbourne: CPI Antony Rowe, 2009.

[34] V. R. Vuchic, Urban Transit Operations, Planning And Economic, John Wiley \& Sons, New Jersey, NJ, USA, 2005.

[35] V. A. Profillidis, Railway Management and Engineering, Ashgate, Surrey, UK, 4th edition, 2014.

[36] N. Harris, H. Haugland, N. Olsson, and M. Veiseth, An Introduction to Railway Operations Planning, A \& N Harris, London, UK, 2016.

[37] A. Ceder, "Public Transport Scheduling," in Handbook of Transport Systems and Traffic Control, J. K. Button and D. A. Hensher, Eds., pp. 539-558, Elsevier Science ltd., Oxford, UK, 1st edition, 2001.

[38] A. Caprara, L. Kroon, M. Monaci et al., "Chapter 3 Passenger Railway Optimization," in Handbooks in Operations Research and Management Science, C. Barnhart and G. Laporte, Eds., vol. 14, pp. 129-187, 2007.

[39] M. Veiseth, P. M. Hegglund, I. Wien, N. O. E. Olsson, and $\varnothing$. Stokland, "Development of a punctuality improvement method," TQM Journal, vol. 23, no. 3, pp. 268-283, 2011.

[40] M. Samà, A. Ariano, F. Corman, and D. Pacciarelli, "A variable neighbourhood search for fast train scheduling and routing during disturbed railway situations," Computers \& Operations Research, vol. 78, pp. 480-499, 2017. 
[41] S. Tschirner, The GMOC Model: Supporting Development of Systems for Human Control [Ph.D. dissertation], Uppsala University, Uppsala, Sweden, 2015.

[42] A. Gunnarsson, "Swedish Railway Policy in the EU Environment - Railway organization and financing," in Proceedings of the Workshop in Stockholm, Ministry of Enterprise, Energy and Communications Sweden, September 2013.

[43] Network Rail, The Network Code, Network Rail, London, UK, 2017.

[44] D. B. Netz, Network Statement 2018, Frankfurt am Main: DB Netz, 2017.

[45] ProRail, Network Statement 2017, ProRail, Utrecht, Netherlands, 2016.

[46] Swedish Transport Administration, Analysmetod och samhällsekonomiska kalkylvärden för transportsektorn: ASEK 6.0, Trafikverket, Borlänge, Sweden.

[47] P. Ström, "Interviewed by the corresponding author on September 15, 2017".

[48] R. M. P. Goverde and I. A. Hansen, "Performance indicators for railway timetables," in Proceedings of the 2013 IEEE International Conference on Intelligent Rail Transportation, IEEE ICIRT 2013, pp. 301-306, September 2013.

[49] C. W. Palmqvist, N. O. E. Olsson, and L. Hiselius, "An Empirical Study of Timetable Strategies and Their Effects on Punctuality," in Proceedings of the the 7th International Conference on Railway Operations Modelling and Analysis (Rail Lille 2017), 2017.

[50] Swedish Transport Administration, Noder i järnvägssystemet, Trafikverket, Borlänge, Sweden, 2015.

[51] Swedish Transport Administration, Riktlinjer täthet mellan tåg, Trafikverket, Malmö, Sweden, 2016.

[52] Swedish Rail Administration, Riktlinjer för tidtabellskonstruktion för tåg på statens spåranläggningar, Swedish Rail Administration, Borlänge, Sweden, 2000.

[53] M. J. C. M. Vromans, Reliability of Railway Syste [Ph.D ERIM], Research in Management 62, 2005.

[54] R. Rudolph, "Allowances and Margins in Railway Scheduling," in Proceedings of the World Congress on Railway Research, pp. 230-238, 2003.

[55] L. Haldeman, Automatische Analyse von IST-Fahrplanen [M.S. thesis], Quoted in Vromans (2005), ETH Zürich, Zürich, Switzerland, 2003.

[56] UIC, UIC Code 451-1 Timetable Recovery margins to guarantee timekeeping - Recovery margins, International Union of Railways., Paris, France, 2000.

[57] J. R. Hammerton, "Delivering solutions for a changing business world," Transactions on the Built Environment, vol. 18, 1996.

[58] H. Sipilä and A. Lindfeldt, Interviewed by the corresponding author on April 9, 2015.

[59] M. Backman and J. Mattisson, Interviewed by the corresponding author on May 11, 2015.

[60] M. Aronsson, M. Forsgren, and S. Gestrelius, "The Road to Incremental Allocation \& Incremental Planning," SICS Technical Report 2012:09, ISSN 1100-3154, Swedish Institute of Computer Science, Kista, Sweden, 2012.

[61] P. Kreuger, M. Aronsson, J. Ekman, and T. Franzén, "Rail Traffic Requirements Engineering," SICS Technical Report 2005:12, ISSN 1100-3154, Swedish Institute of Computer Science, Kista, Sweden, 2005.

[62] M. Forsgren, M. Aronsson, S. Gestrelius, and H. Dahlberg, "Opportunities and challenges with new railway planning approach in Sweden," SICS Technical Report 2012:11, ISSN 11003154, Swedish Institute of Computer Science, Kista, Sweden, 2012.

[63] S. Gestrelius, M. Bohlin, and M. Aronsson, On the uniqueness of operation days and delivery commitment generation for train timetables, presented at RailTokyo 2015.

[64] M. Aronsson, M. Forsgren, and S. Gestrelius, "Uncovered capacity in Incremental Allocation," SICS Technical Report T2017:01, ISSN 1100-3154, Swedish Institute of Computer Science, Kista, Sweden, 2017.

[65] V. Svedberg, M. Aronsson, and M. Joborn, "Railway Timetabling Based on Cost-Benefit Analysis," Transportation Research Procedia, vol. 22, pp. 345-354, 2017.

[66] E. Andersson, A. Peterson, and J. Törnquist Krasemann, "Robustness in Swedish Railway Traffic Timetables," in Proceedings of the RailRome 2011: Book of Abstracts 4th International Seminar on Railway Operations Modelling and Analysis, 2011.

[67] A. Peterson, "Towards a robust traffic timetable for the swedish southern mainline," in Proceedings of the Computers in Railways XIII: Computer System Design and Operation in the Railway and Other Transit Systems, pp. 473-484, 2012.

[68] F. Khoshniyat and A. Peterson, "Robustness Improvements in a Train Timetable with Travel Time Dependent Minimum Headways," in Proceedings of the 6th International Conference on Railway Operations Modelling and Analysis - RailTokyo, Tokyo, Japan, March, 2015.

[69] S. Gestrelius, M. Aronsson, M. Forsgren, and H. Dahlberg, "On the delivery robustness of train timetables with respect to production replanning possibilities," in Proceedings of the 2nd International Conference on Road and Rail Infrastructure, 2012.

[70] F. Khoshniyat, Optimization-Based Methods for Revising Train Timetables with Focus on Robustness, Linköping University Electronic Press, 2016.

[71] E. V. Andersson, A. Peterson, and J. Törnquist Krasemann, "Quantifying railway timetable robustness in critical points," Journal of Rail Transport Planning and Management, vol. 3, no. 3, pp. 95-110, 2013.

[72] J. Warg and M. Bohlin, "The use of railway simulation as an input to economic assessment of timetables," Journal of Rail Transport Planning and Management, vol. 6, no. 3, pp. 255-270, 2016.

[73] E. V. Andersson, A. Peterson, and J. Thörnquist Krasemann, "Reduced railway traffic delays using a MILP approach to increase robustness in Critical Points," Journal of Rail Transport Planning \& Management, no. 5, pp. 110-127, 2015.

[74] E. Solinen, G. Nicholson, and A. Peterson, "A Microscopic Evaluation of Robustness in Critical Points," in Proceedings of the 7th International Conference on Railway Operations Modelling and Analysis (RailLille 2017), pp. 83-103, 2017.

[75] M. Forsgren, M. Aronsson, P. Kreuger, and H. Dahlberg, The Maraca: a tool for minimizing resource conflicts in a non-periodic railway timetable. Presented at RailRome, 2011.

[76] M. Forsgren, M. Aronsson, S. Gestrelius, and H. Dahlberg, "Using timetabling optimization prototype tools in new ways to support decision making," WIT Transactions on the Built Environment, vol. 127, 2013

[77] S. Gestrelius, M. Aronsson, M. Joborn, and M. Bohlin, "Towards a comprehensive model for track allocation and roll-time scheduling at marshalling yards," Journal of Rail Transport Planning Management, vol. 7, no. 3, pp. 157-170, 2017. 
[78] J. T. Krasemann, "Design of an effective algorithm for fast response to the re-scheduling of railway traffic during disturbances," Transportation Research Part C: Emerging Technologies, vol. 20, no. 1, pp. 62-78, 2012.

[79] J. T. Krasemann, "Computational decision-support for railway traffic management and associated configuration challenges: An experimental study," Journal of Rail Transport Planning and Management, vol. 5, no. 3, pp. 95-109, 2015.

[80] S. Kvale, Den kvaliativa forskningsintervjun (The Qualitative Research Interview, in Swedish), Studentlitteratur, Lund, Sweden, 1997.

[81] M. Hammersley and P. Atkinson, Ethnography: Principles in Practice, Routledge, 3rd edition, 2007.

[82] H. Olink and G. Scheepmaker, RailSys use by RailwayLab. Presented at Railsys Swedish and Scandinavian User Group 2017, at the Royal Institute of Technology in Stockholm, Sweden, 2017.

[83] C. W. Palmqvist, N. O. E. Olsson, L. Winslott Hiselius, and L. Winslott, "Punctuality Problems from the Perspective of Timetable Planners in Sweden," in Proceedings of the 20th EURO Working Group on Transportation Meeting, EWGT 2017, Budapest, Hungary, September 2017. 


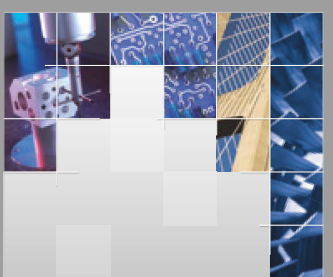

\section{Enfincering}
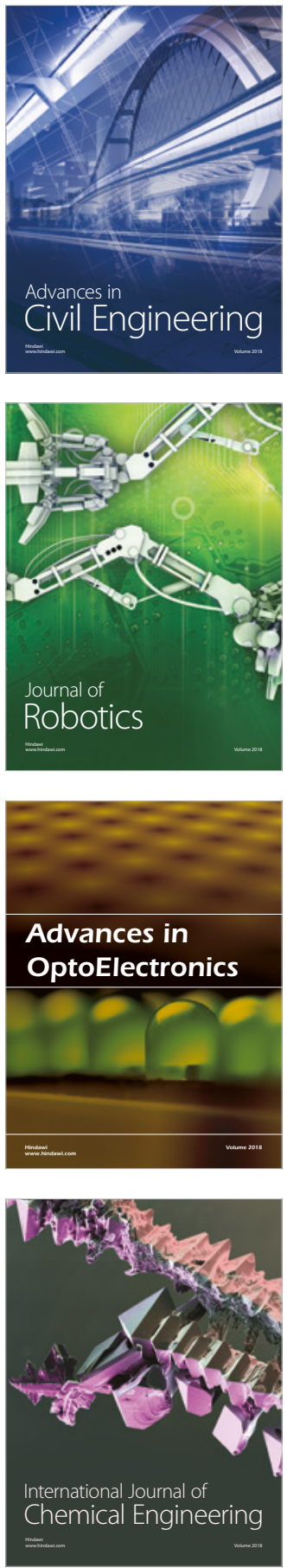

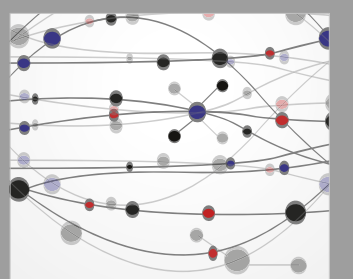

\section{Rotating \\ Machinery}

The Scientific World Journal

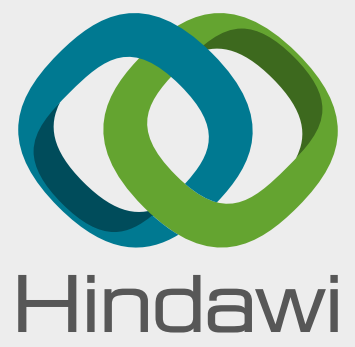

Submit your manuscripts at

www.hindawi.com
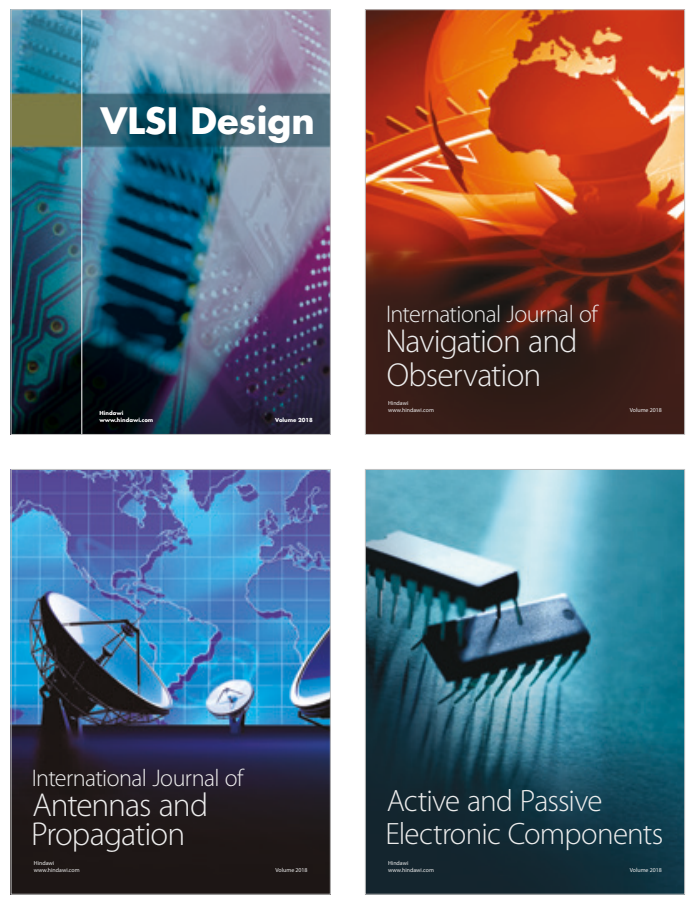
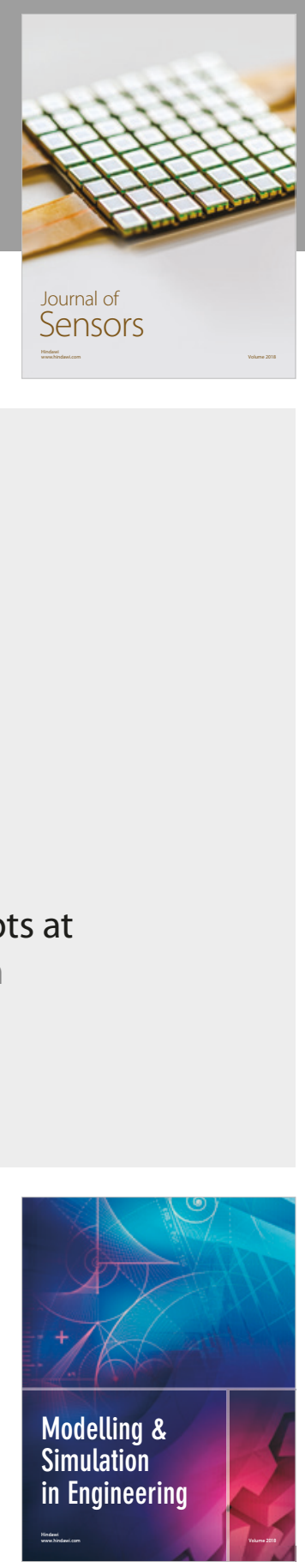

\section{Advances \\ Multimedia}
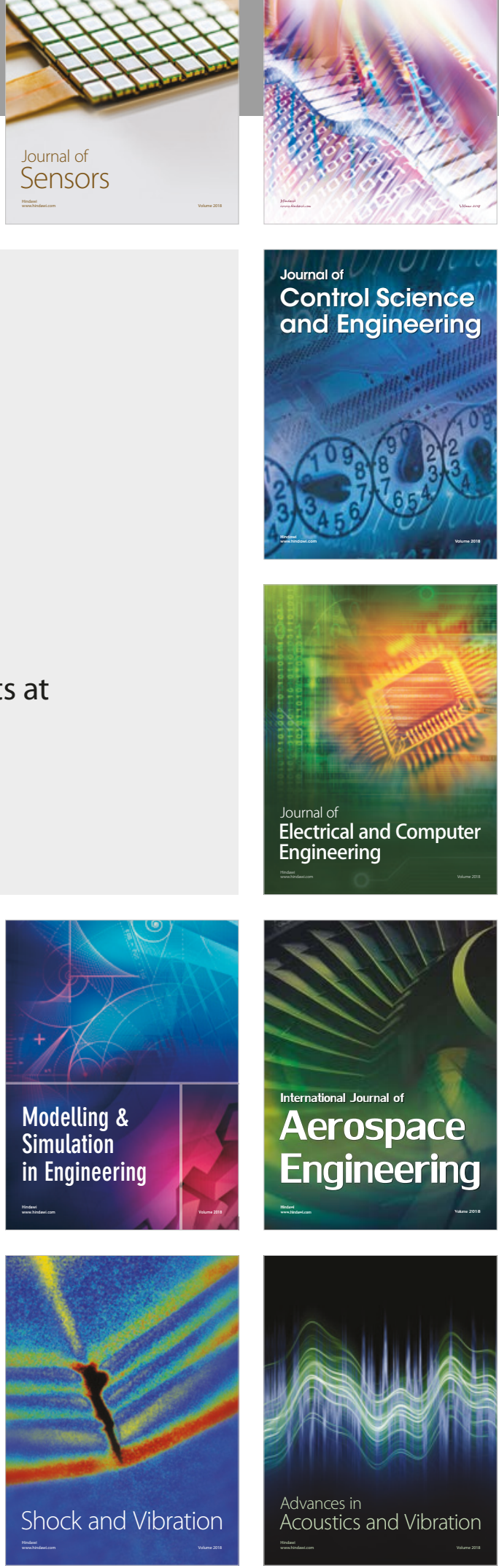